\title{
Urbanization; Construction or Destruction?A Viable Way Out
}

\author{
Bage John Bage
}

Department of Architecture, Ahmadu Bello University, Zaria-Nigeria

Doi:10.5901/mjss.2014.v5n26p51

\begin{abstract}
Regenerative architecture is an emerging scheme that aims at and emphasises on the need to maintain the natural environment and its characteristic features with a focus on doing more that sustainable architecture attempts. In this, the sustenance of natural resources harnessed and used from the immediate environment (site) is key. However, the common attitude to this in Nigeria and several African countries is an attempt to develop the built environment with little or no considerations to the need for reuse and recycling. If this seems to be a mirage that is only considered theoretically, how can this beactualised practically? This study considers the fact that for a building to be eco-friendly, regenerative principles need to be adopted for its design, thus emphasising renewal of used resources and maintenance of the same. It will also reveal various ways in which regenerative architecture principles can be implemented on the use of locally available resources in a locality. It emphasises the need for the implementing of such principles in the design of resorts which are primarily supposed to provide an environmentally friendly atmosphere for guest. It further suggests recommendations for the design of eco-friendly buildings using regenerative principles. This hopes to serve as a bench mark for advancing the development of buildings that will function in a regenerative manner.
\end{abstract}

\section{Introduction}

Change is a phenomenon that has existed from time immemorial; it is constant and ever dynamic transforming and translating things, people and events from one form to another. Development is defined from the root word "develop" referring to growth, conversion to a new purpose or to advance in a process which is denoted by definite changes of state, form and nature (Oxford Dictionary, 2006)

The Chambers dictionary (1999) defines development as a process of unravelling the latent capacity and potentials of an item thus, making it more usable or useful. Being a process development wherefore involves a series of stages and these successive stages would usually aim at advancing progressively some degree of change in the raw item from the preceding stage.

Human history suggests that development has been central in the quest for civilization over the ages. Consequently Architectural pursuits have varied in focus from Palaeolithic times through the Mesolithic and unto Neolithic and Modern times on different ideas for the sake of betterment of the built environment. These human cravings over the ages have been a search for a better life and living conditions. One very popular aspect is sustainability which refers to utilization, optimization, maximization, and conservation (Oxford Dictionary, 2006).

The term sustainability has occurred in recent times in every aspect of human development to stress how needful it is to human existence. Sustainable development thus has been defined in several ways but most commonly as development that "meets the needs of the present without compromising the ability of future generations to meet their own needs" (International Union for Conservation of Nature (IUCN), 1980).

This was furthered and popularized in 1987 by the United Nations World Commission on Environment and Development (WCED), commonly called the Brundtland Commission.

The concept of sustainability has emphasized

- Using resources efficiently and minimizing the consumption of raw material resources (energy, water, land, and materials) during the construction and life of a building facility;

- Maximizing the reuse of resources harnessed for building from natural sources;

- Seeking out renewable energy sources as opposed to using fossil fuels in building and construction;

- Creating a healthy environment for workers in the building industry, clients and their visitors, and neighbours;

- Designing facilities for long term durability, flexibility, and eventual reuse; and

- Protecting and restoring the natural environment. 
However it must be noted that the sustainability movement of the Bruntland Commission may not serve all future generations in view of world birth rates and the consequent pressure on the earth's finite resources. This loop hole is therefore the interest of Regenerative thinking and design to protect, restore and replenish.

The result of the industrial revolution is what we majorly would characterize as the modern civilization which sits on a backdrop of the ancient civilizations. It is responsible also for the urbanization and the notable development of the built environment.

This industrial development which is dominant is a linear throughput model which generates waste resulting in environmental pollution and degradation especially when the rate of decomposition is lower. Human consumption patterns have had severe consequences and are currently breaching the capacity of earth to absorb.

This is principally notable in;

- Habitat Destruction,

- Resource Depletion,

- Watershed Degradation and

- Waste Generation.

The basic resultant effect is seen when we consider that several developmental models that exist basically encourage consumerism rather than producing the food to sustain it. Nature attempts to contrast this, presenting a model of production and consumption, i.e.; production of raw materials for consumption at every stage of life. It is sort of closed loop in form thus effluents of one organism serve as the food for another.

Furthermore, a cycle is created maintaining a constant material flow exchanging and renewing. This brings us to a point where we can say categorically that there are primarily two models in which any aspect of development falls into. Akihan (2013) in his documentation on Regenerative architecture enumerated these two models as: Throughput System Model, Regenerative systems Model

These two have a primary difference which is seen prominently in their end goals.

\section{Throughput System or Model}

This model centrally sees consumption as being very vital in as much as there is and efficiency in the working and functioning of setups.

\section{Existing throughput systems}

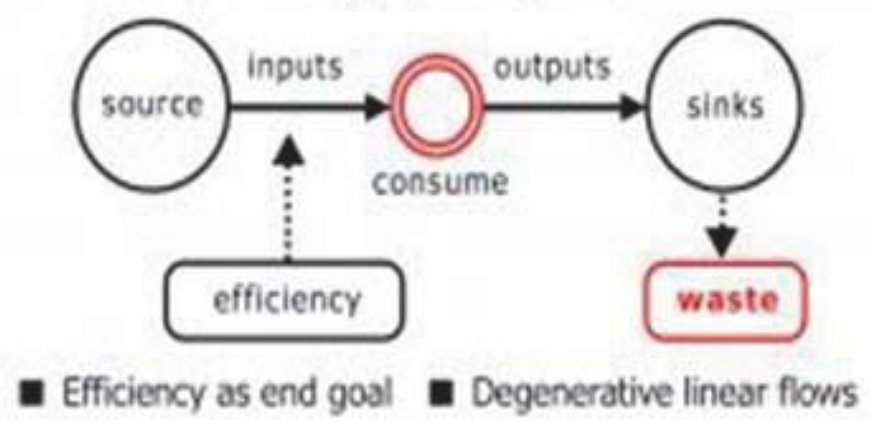

Figure I: Existing Throughput System or Model

Source: 2013 Hub Pages Inc.

This much of human consumption in the process of production of appears as a major concern since as stated above the primary objective has been efficiency as the end goal. Several stages of human existence have proved to focus on this and hence the depletion of forest reserves and fossils and other sources of energy. The industrial revolution cannot be said to be the very commencement of this since poaching on wild life without considering extinction hazards have existed long before the industrial revolution. However, even in the current sustainability drive, efficiency has very much been the main focus of efforts (Akihan, 2013). 


\section{Regenerative Systems Model}

By contrast, regenerative systems don't act as the throughput but rather have a focus which aims at effectiveness of the whole process. Here the overall goal is to ensure that whatever is developed is practically and effectively solving the basic problem or need for which it was conceived. This has in mind that inasmuch as individual systems are effective this will on a large scale result in whatever efficiency is desired but without effectiveness efficiency becomes impossible.

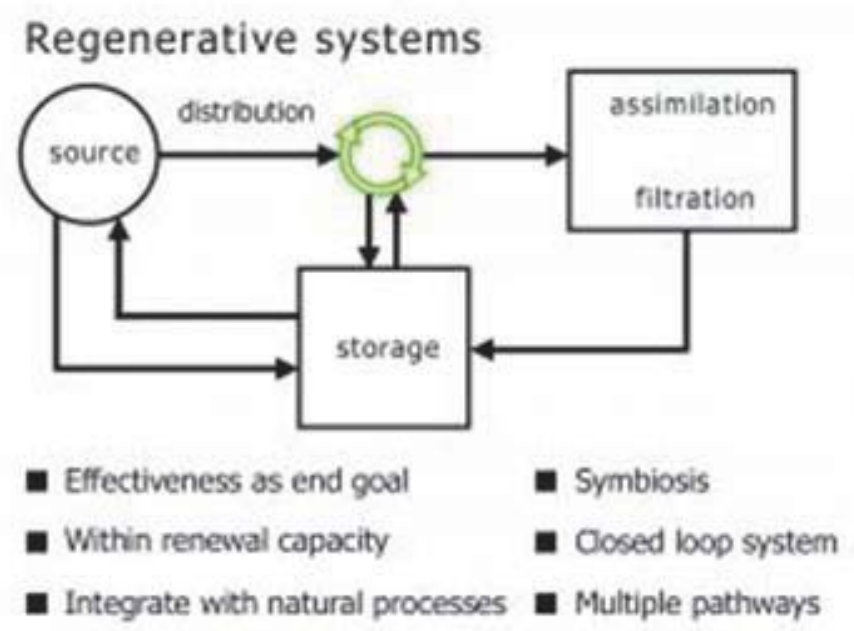

Figure II Regenerative systems Model

Source: 2013 Hub Pages Inc.

Therefore regenerative thinking seeks to replace the concept of efficiency which is an outcome of a consumptive attitude emphasizing the need to ensure that every form of consumption is made to result in production of food for subsequent processes of development rather than the generation of waste which results in degradation and destruction of the ecosystem. This, is culminated into a set of principles which serve as a guide to achieving effectiveness via regenerative systems and architecture, these principles are as expanded below:

1. Effectiveness - The main concern of this is making good decisions. Considering the good of all existing species within the system is the goal, this is possible only if all species are thought of during every process of development (consumption). Akihan (2013) states that "we are not detached from the ecosystem and we need to start to recognize that what is good for us may not be good at all for the ecosystem."

2. Closed looped system - This is explained in terms of a build-up of processes which result in a chain reaction which repeats itself in a resonating manner such that it never comes to a conclusion. This need to design remaking our production processes has a view of materials flowing in a cycle therefore removing the concept of waste. Such systems are usually termed industrial ecology. This ecosystem makes efforts so consumption of energy and materials are optimized, while minimizing waste generation and effluents of a process serve as the raw material in another.

3. Integrating human processes with the natural - the basic processes involved in metabolic action of the human body require the components of nature ranging from gases to liquids and solids. Wherefore the need to start to redesign our processes to achieve a balance with nature and its processes to protecting and reinforcing them even while consuming their resources.

4. Symbiosis between different elements - this relates to the interdependence that needs to exist between whatever we build up and the natural environment. Thus designing our systems to provide for mutual benefits. This is instead of the parasitic attitude of taking from nature and only returning destructive waste to it.

5. Multiple pathways - Multiplicity in patterns of achieving goals focuses on making for system resilience. By contrast the efficiency theory of throughput systems bears only one method as being best, as against effectiveness here, which creates dynamism. Such an example is the several means responsible for precipitation and water supply for plant growth. 
6. Within renewal capacity - The major cause of degradation is wear and tear of systems due to overuse and inadequacy of maintenance. Hence, regenerative systems must work within the carrying capacity. This brings about the need for an optimal point to checkmate any excesses which will degenerate the system.

In addition to the already stated principles of regenerative systems other sets of design guidelines that present ideas worthy of consideration in the employment of regenerative architecture are:

\section{Development in the Built Environment}

The built environment is simply regarded as the natural world, especially as affected by human activity in a bid at achieve development consisting of buildings, service structures and landscaping (Oxford Dictionary, 2006). World civilizations have been a constant advancement on the natural environment in terms of buildings, road construction and other features. Development in the built environment therefore entails the various attempts to advance on the building structures, building materials and methods of construction.

Sustaining the natural environment and its constituent resources in the process of developing the built environment propelled the sustainability movement of the 1980's and in the same vein the Regenerative ideas of the 1990's. Peter Clegg of theFeilden Clegg Bradley Studios UK suggests this produces "built form and infrastructure that begins to 'heal the wounds' that have already occurred."(Clegg, 2012)Regenerative design and development focuses on enhancing life for humans and, other species, and ecological systems as a whole (Cole, 2012).

\section{Subdivisions of the Built Environment}

Built-up areas: inclusive are the various categories of buildings which may be residential, industrial or institutional as the case may be serving respective purposes too. It is important to note that building have related structures that may provide auxiliary or ancillary services to users of the buildings.

Landscapewhich is often categorized as either hard or soft and in total consisting of streetscape, pavements, Lawns and gardens, ponds and pools and so on. This is a combination of natural features and artificial or manmade items of the physical environment. These are mostly part of the outdoor environment.

\section{Ecology}

According to the Webster dictionary ecology is a scientific study of the processes influencing the distribution and abundance of organisms, interactions among organisms, and with other flux of energy and matter. Simply put, it is the study of the ecosystem and its working, basically considering the interaction or relationship of the physical and biological environment.

The physical environment comprises the Lithosphere, atmosphere and stratosphere; Light and Heat or Solar Radiation, Moisture, Wind, Oxygen, Carbon Dioxide, Nutrients in Soil, Water, Atmosphere, solid minerals and the built areas.

The biological environment includes the biosphere and its related organisms;Plants and Animals.

These components of the physical and biological environment are referred to as natural resources and can be grouped into two categories namely;Renewable and Non-renewable

Renewable resources are replaceable after use and over time by natural processes however,non-renewables are not replaceable or can only be replaced over extremely long periods of time.

Ecology draws upon other fields and indeed contributes to the study and understanding of environmental problems. Introduced by the German biologist Ernst Heinrich Haeckel in 1866; the term ecology is derived from the Greek 'oikos' ("household"), from the same root word as economics. Thus, it implies the study of the economy of nature.

The Cary School of Ecosystem Studies (CSES) further present's three pervasive definitions of ecology stemming from the Haeckelian form --as the study of the relationship between organisms and environment, the study of the distribution and abundance of organisms Andrewartha and Birch, (1954) and thirdly as being the study of ecosystems Odum, (1971).

Ecosystem, a word coined in 1935 by the British plant ecologist Sir Arthur George Tansley stresses the concept of each habitat as an integrated whole. Since a system is a collection of interdependent parts that function as a unit involving inputs and outputs. The major parts of an ecosystem (ecological system) are the biotic: producers, the consumers, the decomposers, and the non-living or abiotic component, consisting of dead organic matter and nutrients in the soil and water. Inputs and Outputs result in the interaction. 
Conservation denotes a sustainable use and protection of natural resources. The goal of which is targeted at renewable resources and ensuring that such resources are not consumed faster than they are replaced. In the case of the non-renewable conservation aims at checking consumption rates to avoid exhausting the limited supply through waste (CSES)

\section{Harnessing the Natural Environment for Development}

Maintaining the natural environment has always been termed as man's primary responsibility as stewards of the earth from time immemorial despite the need to harness its abundant wealth of resources which has resulted in humans treating the environment with disdain (Ogundele, 2003/2004). However it is obvious that a host of developing nations of the world, Nigeria inclusive have relegated the responsibility of environmental sustainability and maintenance to the background (Berry 1993 In: Ogundele, 2003/2004). Ogundele, (2003/2004) asserts that this has resulted in a problem of environmental devastation in Nigeria and the world over.

In recent years the issue of environmental sustainability has been referred to as a major responsibility of government to enforce if any head way is to be made in the efforts to combat the resultant scourge caused by negligence. Haruna (2014) argues that experts are of the opinion that enshrining sustainable climate resilient green development in a nation's constitution is the only way to checkmate the steady depletion of the natural environment and other resources of a country and the world at large.

In furtherance, Haruna (2014) points out the fact that Nigeria's environmental problem are acute and responsible for the over 50 erosion sites along about $1000 \mathrm{~km}$ of the coastline and these keep escalating due to traditional deforestation for fuel and Saharan desertification. This is obviously disturbing that despite these the 1999 constitution of the Federal Republic of Nigeria mentions the environment but once and in an ambiguous manner as argued by many environmental experts. Hence how Can these unabated negative impacts on the environment be curtailed? Oladapo (2014) In: Haruna (2014) opined that Nigeria's quest for national development will only be meaningful if it does not increase the nation's vulnerability to environmental problems.

The building or construction industry has been identified as one major contributor to environmental destruction (Adeniji, 2008 In: Usman Et'al, 2013) thus the need to consider carefully building and construction activities which utilize the environment as a major raw material. Buildings and their adjoining components namely; roads and other functional spaces are considered a definite measure of development and these also refer to the built environment. If development must yield positive impacts, then the increasing emission of greenhouse gases which result mainly from human activitiesand buildings in particular (America Institute of Architects, In: Williams, D. E. 2006), must be checked.

It is important therefore to enumerate and also outline the resultant consequences of poor environmental activities in other that a better awareness be established through enlightenment of the general populace. However, Onwueme and Bosari (2007) In: Abolore (2012) opined that all effort to enlighten the populace may not result in a thorough understanding and adherence to the underpinnings philosophies of sustainability therefore the need to emphasize compliance by professionals in the environmental field of development.

In consonance with this Celik (2013) states that professionals in the building industry must reevaluate their development approaches. Notwithstanding, it needs to be noted that it is insufficient for Architects, Engineers, Builders and other building professionals to understand the basics of sustainable development incorporating these in their work. Moreover sustainability is a concept that evolves based on time, location, and intent and so must be approached from conceptual levels to achieve its aim in a continuously changing global world (Celik, 2013).

\section{Unsustainable/ Non-Regenerative Practices in Development (Destruction or Construction)}

\subsection{Effects of poor Building Activities on the Environment}

Several building activities which try to utilize the natural environment deplete huge amounts of resources. Urbanization negatively impacts the environment mainly by the production of pollution, the modification of the physical and chemical properties of the atmosphere, and the covering of the soil surface (UHI, 2014) with non-life-sustaining eco-friendly substances. These negate human and environmental health adversely.

The direct opposite of positive development or building up is a product of deliberate efforts to put an end to a process or an indirect means which may result due to negligence. This may also be as a result of wearing and tearing of systems.

Every resource or item is subject to deterioration over time under use. Degradation and destruction are direct 
opposite of positive development and these often results from misuse or overuse with poor or no maintenance. Therefore although deterioration may result from wear and tear it is either directly or indirectly due to negligence. Some of these poor practices include excessive clearing, Quarrying, deforestation, non-replacement of greens, hard landscaping, poor material choice and use, wrong construction methods and water contamination and misuse.

\section{Consequences/Related phenomena}

\subsection{Climate Change}

This refers to a significant change in the climaticmeasures over an extended period of time including major changes in temperature, precipitation, or wind patterns and other climatic variables (Environmental Protection Agency (EPA), 2014). This change can increase or decrease rainfall, influence agricultural crop yields, affect human health, cause changes to forests and other ecosystems, or even impact our energy supply. The Natural Resources Defense Council(NRDC) estimates that carbon dioxide and other greenhouse gas emissions responsible for global warming collect in the atmosphere like a thickening blanket, trapping the sun's heat and causing the planet to warm up at extremely increasing rates yearly.

Although the effects may increase our reliance on renewable energy from wind, solar and geothermal sources will conserve energy thereby checking the rate of global warming.

\section{Urban Heat Island}

Heat island is an urban climatic phenomenon referring to parts of the urban landscape where there is a steep temperature variation between that area and cooler surrounding areas (Balu, 2010).Infrastructural development transforms the environmental components from open land and vegetation to buildings, roads, and other infrastructure and from permeable and moist to impermeable and dry forms thereby enhancing the creation of Urban Heat Islands. Although heat island effect may lengthen the plant-growing season, it negatively results in:

- Increased energy consumption for cooling

- Greater emissions of air pollutants and greenhouse gases

- Compromised human health and comfort caused by higher temperatures in the form of respiratory difficulties, heat cramps and exhaustion, non-fatal heat stroke, and death.

- Impaired water quality and damage of aquatic ecosystems due to excess discharge of heat into water bodies.

\section{Global Warming}

The invariable warming up of the earth due to collections and accumulation of Greenhouse gases emitted from human industrial and daily activities is termed global warming. These activities and their gas emissions consist of four significant gases called greenhouse gasses. These include carbon dioxide, methane, nitrous oxide, and fluorinated gases. These air pollutants that collect in the atmosphere act like a thickening blanket, trapping the sun's heat and causing the planet to warm up (NRDC, 2014). The resultant effect is increased temperatures, irregular weather and climate patterns and rising sea levels and floods.

\section{The Way Around this- Possible Solutions}

Building conservation practice can broadly be described as the development of socially and environmentally sustainable design within the historic built environment which responds to and respect its immediate surroundings and which values memory, identity and continuity with the past (The University of Sheffield, 2013)

Eco-friendly design and construction aims at conservation and Conservation views the complex connections between natural resources and seeks to balance resource use with protection to ensure an adequate supply for future generations, achieved via a variety of methods. These include reducing consumption of resources; protecting them from contamination or pollution; reusing or recycling resources when possible; and fully preserving, resources.

\section{Achieving Eco-Friendliness}

The extinction of plants and animals as a result of human activities has a long history. The rate of species extinction is 
considered to be catastrophically high. It is estimated to be between one thousand and ten thousand times the rate before the impact of humans on the environment became significant (Wilson, 2002 In:Sassi, 2006).

A major focus on the peculiar features that foster eco-friendliness namely; Site and land use, Community, Health and well-being, Materials, Energy, and Water is necessary (Sassi, 2006). This will ensure a minimizing of destructive patterns of life and conversely work towards conservation. The Waitakere city council (1996) enumerated the following as guidelines to consider for ecofriendly houses and a better and healthier environment.

\subsection{Site and land use}

This will involve selecting sites with care, using land efficiently, minimizing impact of development (destruction during construction), healthy use patterns and practices.

\subsection{Community (Designing for sustainable communities)}

Recognizing and enhancing the peculiar social capital, providing for basic needs, enhancing the quality of life, and promoting sustainability with a focus on the locale and the locals

\subsection{Health and well-being}

This aims at enhancing the Attributes of a healthy life and checking all Causes of ill health.

Since overwork, drudgery, continual sordid anxiety, ill housing, deprivation of nature's beautyand amusement hamper on bodily conditions depriving good health (Morris, 1884 In:Waitakere city council, 1996)

\subsection{Materials}

Minimizing the need of materials through conservative use, using existing materials, designing to enable future buildings and material reuse and recycling, selecting new materials with care.

\subsection{Designing to reduce $\mathrm{CO}_{2}$ emissions and pollution}

Is a focal item since it ensures a reduction in energy requirements, using energy efficiently, and above all using 'green' energy sources as against the non-green.

\subsection{Sustainable water use and wastewater disposal}

This has a focus on minimizing the need for water, using water efficiently, recycling used water, recycling rainwater, reducing the use of mains drains

Building conservation practice can broadly be described as the development of socially and environmentally sustainable design within the historic built environment which responds to and respects its immediate surroundings and which values memory, identity and continuity with the past. Growing recognition of the social, cultural and financial asset of existing buildings and spaces has placed built heritage issues high on national government policy agendas and conservation principles figure prominently in the successful physical and economic regeneration of the built environment.

Having enumerated how vital eco-friendly practices can save our depleting environment it must further be emphasized that except regenerative perspectives are considered eco-friendliness will not be sustained over time due to increased population and dependence on finite depleting resources.

\section{References}

Abolore, A.A. (2012). Comparative Study of Environmental Sustainability in Building Construction in Nigeria and Malaysia.Journal of Emerging Trends in Economics and Management Sciences (JETEMS) 3(6):951-961(ISSN:2141-7024) http://jetems.scholarlinkresearch.org/articles/

Akihan,(2013) Regenerative Architecture | Beyond Sustainability - Design to Actively Heal the Environment. Ecosystem restoration: http://www.oberlin.edu/akihan.hubpages.com/, Inc.

America Institute of Architects, In: Williams, D. E. (2006).Sustainable Design: Ecology, Architecture and planning. John Wiley \& Sons, 
Inc., Hoboken, New Jersey

Balu, S. (2010). What are Urban Heat Islands?: Bright Hub Engineering Inc. 2012. Accessed June 2014

Berry (1993): in Ogunleye, F, (2003/2004) Environmental Sustainability in Nigeria: The "Awareness" Imperative African Issues Vol. 31/32, Vol. 31, no. 1/2 - Vol. 32, no. 1/2 (2003/2004), pp. $41-52$ African Studies Association : http://www.jstor.org/stable/1535099

Cairns, J. 2007.Sustainable Co-evolution.International Journal of Sustainable Development and World Ecology 14 (2007):103-108.

Celik, B. G. (2013). Exploring Sustainable Development and Its Interpretation in the Built

Environment.Journal of Sustainable Development:Vol 6, No 12 (2013) :ISSN 1913-9063 (Print) ISSN 1913-9071 (Online)http://www.ccsenet.org/journal/index.php/jsd/article/view/30923

Clegg, P. (2012).Commentary: A Practitioner's View of the "Regenerative Paradigm." Building Research \& information 40.3 (2012): 365368.

Cole, R.J. (2012). Regenerative Design and Development; Current Theory and Practice. Building Research \& Information 40.1 (2012): 16.

Cole, R.J.\& Oliver, A 2012.The Next Generation. Technical CANADIAN ARCHITECT 08/12 (2012):29-30

Haruna, G. (2014). Nigeria: Making Environmental Rights Justiceable. This Day May 2014http://allafrica.com/misc/info/copyright.html

Ogunleye, F, (2003/2004) Environmental Sustainability in Nigeria: The "Awareness" Imperative African Issues Vol. 31/32, Vol. 31, no. $1 / 2$ - Vol. 32, no. 1/2 (2003/2004), pp. 41-52 African Studies Association : http://www.jstor.org/stable/1535099

ProVention Consortium, (2007).Tools for Mainstreaming Disaster risk reduction; Construction Design, Building Standards and Site Selection: The International Federation of Red Cross and Red Crescent Societies / the ProVention Consortium. http://www.proventionconsortium.org

Sassi, P. (2006). Strategies for Sustainable Architecture, Taylor \& Francis 2 Park Square, Milton Park,

Abingdon, Oxon OX14 4RN/ Taylor \& Francis Inc 270 Madison Avenue, New York, NY10016 Taylor \& Francis Group, an informal business

Tainter, J.A.(2012).Regenerative Design in Science and Society.Building Research \& Information 40.3 (2012): 369-372.

Usman, T. O; Paul, S. O; \&Ochala, M, (2013).Green Audit and Environmental Sustainability in

Nigeria: Unveiling Corporate Perspectives, International Journal of Public Administration and Management Research (IJPAMR), VOLUME 2, NUMBER 1, OCTOBER, 2013. Research Centre for Management and Social Studies Website: http://www.rcmss.com ISSN 2350-2231(Online) ISSN 2346-7215(Print)

Waitakere city council (1996) Eco-friendly design Guidelines.

Basic Information_Heat Island Effect__U.S. EPA.htm Accessed June 2014

Basic Information_Climate Change__U.S. EPA.htm Accessed June 2014

The Urban Heat Island (UHI) Effect.Urban Heat Islands (UHIS).htmAccessed June 2014

http://www.caryinstitute.org/discover-ecology/definition-ecologyAccessed June 2014

http://www.sheffield.ac.uk/architecture/study/pgschool/taught_masters/macrAccessed June 2014

http://www.regenesisgroup.comAccessed June 2014 